\title{
La singularidad del ser humano como animal bio-cultural
}

\section{I.El ser humano en permanente redefinición}

os seres humanos somos la única especie animal autoconsciente de sí misma y, por ello, capaz de preguntarse y cuestionar su propia realidad. Y lo ha hecho siempre, de una manera más o menos consciente, más o menos profunda, desde el primer momento de su existencia como especie ${ }^{1}$. Desde este punto de vista, podríamos definirnos como un animal inquiriente o animal preguntón ${ }^{2}$. Este rasgo no es una característica ociosa, accidental, de la que el ser humano pueda prescindir, sino algo que corresponde a su propia esencia y condición: necesita saber de sí y tener una idea de sí mismo para orientar su propia realización, en la medida en que, por poseer una naturaleza abierta, su realización depende de sus propias decisiones, entre ellas acertar en el empeño de alcanzar con éxito la meta ideal que sobre sí se ha construido. Se da, por tanto, en la estructura esencial del ser humano una estrecha relación entre autoconocimiento y autorrealización.
Basta echar una mirada a la historia humana para percatarse de la interminable secuencia de modelos antropológicos que se han ido proponiendo y sucediéndose regularmente como consecuencia de los cambios de mentalidad producidos por todo tipo de crisis culturales o cosmovisionales, deudores todos ellos de la inevitable evolución de los saberes científicos acerca de la realidad y del propio ser humano. Si estos avatares se han producido siempre de forma intermitente ${ }^{3}$, apareciendo en esa historia la radical problematicidad del ser humano, es en la actualidad cuando parece haberse percatado de un modo más profundo de su radical e inevitable problematicidad ${ }^{4}$. Efectivamente, el hombre actual se halla en un momento de seria transformación y de crisis de su propia identidad, de reacomodo de muchos de los rasgos que definían su ser hace algo más de un siglo y medio. Con la aparición del paradigma evolutivo, y más en concreto con las propuestas de Charles Darwin sobre la selección 
natural, el modelo antropológico que había predominado en Occidente comenzó a tambalearse, pasando de entenderse como alguien creado directamente por las manos de Dios, a experimentarse como una especie más del ámbito de la biosfera, aparecida al igual que las otras como fruto de un similar proceso evolutivo, en el que se conjugan las leyes de la genética con la selección ambiental, según nos indica la teoría sintética de la evolución ${ }^{5}$. Parecería, pues, que estas aportaciones científicas exigirían defender sin paliativos las tesis del naturalismo filosófico o materialismo fisicalista y reduccionista sobre el ser humano y sobre el conjunto de la realidad.

Posteriores e importantes descubrimientos en diferentes esferas científicas han seguido minando la cosmovisión religiosa antropocéntrica en la que estábamos aposentados, confirmándonos más fuertemente en este radical cambio de perspectiva y abocándonos a replantearnos la pregunta por nuestra identidad y nuestro puesto en el conjunto del universo. Nos hallamos en la actualidad en una auténtica edad de oro de disciplinas científicas como la paleoantropología, la genética, la biología molecular, la embriología, la etología y otras muchas, que parecen apuntar hacia una visión del ser humano entroncado en la realidad material y biológica de nuestro mundo, menos autosuficiente y reducido a enten- derse como una especie más del conjunto de la biosfera, producto de leyes evolutivas que parecen regirse, como dijo J. Monod, por la conjugación del azar y la necesidad ${ }^{6}$.

Muchas de las aportaciones de las disciplinas científicas señaladas parecen apoyar incluso, según algunos, no sólo la superación de la concepción teocéntrica del ser humano, sino incluso una visión humanista antropocéntrica. Según este punto de vista materialista y reduccionista, la ciencia nos abocaría a no tener más remedio que defender una visión reductiva y antihumanista del ser humano, es decir, partidaria de entender a la especie humana como una más del largo y complejo proceso evolutivo, todo lo compleja y maravillosa que se quiera, pero nada más.

Por otro lado, y en paralelo a esta visión reduccionista, parecen cobrar cada vez más fuerza los planteamientos de la liberación animal y de los derechos de los animales, que entienden que, aunque la diferencia entre la especie humana y la mayoría de los animales es cualitativa, de grado, no lo es sin embargo respecto a las especies de los denominados grandes simios (chimpancés, bonobos, gorilas y orangutanes), por lo que consideran que hay que ampliar el concepto humanidad y la categoría de persona a los componentes de estas especies, y, en consecuencia, aceptar y cumplir, por parte de los 
seres humanos, una larga lista de derechos humanos a favor de los grandes simios ${ }^{7}$.

La cuestión que aquí vamos a plantear es si las propuestas humanistas y religiosas acerca del ser humano están ya superadas y obsoletas, por incorrectas y acientíficas, o si, por el contrario, siguen teniendo vigencia y base científica, lo que nos indicaría, por el contrario, que los planteamientos reduccionistas a los que hemos hecho referencia, no son tan evidentes ni justificados como los autores que defienden esos planteamientos nos quieren hacer ver. Necesitamos, por tanto, volver a reflexionar y mostrar aqueIlo que constituye lo específico del ser humano, desde el análisis de las novedosas aportaciones de los diversos saberes científicos, para ver en qué medida nos sirven para asentar una correcta visión del ser humano como realidad específica y cualitativamente diferente al resto de las especies animales, según las tesis de la postura humanista.

No cabe duda de que nos hallamos ante un reto decisivo para la comprensión cristiana y humanista del ser humano, y necesitados de una nueva redefinición de nuestro ser y de nuestro puesto en el cosmos (Max Scheler). La estrategia que tenemos que seguir es presentar una breve síntesis de las diferentes aportaciones científicas que nos permitan realizar un ejercicio comparativo entre el ser humano y el resto de los animales, para ver en qué medida tenemos apoyos científicos y filosóficos suficientes para seguir defendiendo el especial puesto del hombre en el conjunto de la biosfera y de todo el universo, o tenemos que adscribirnos a la postura defendida por el naturalismo filosófico y el materialismo reduccionista. En este ejercicio comparativo, pretendemos llegar a examinar los ingredientes fundamentales de la compleja y específica conformación biocultural del ser humano, para tratar de concluir que la especie humana es la única que está constituida por una específica conjunción de biología y cultura, conformando ambos componentes una estructura compleja pero unitaria. Esta unidad bio-cultural supone e implica a su vez una específica unidad psicoorgánica, a caballo entre posturas extremas como los dualismos interaccionistas y los materialismos reduccionistas, defendidos por el conductismo, la teoría de la identidad $y$ determinados funcionalismos ${ }^{8}$. En definitiva, pretendemos llegar a la conclusión de que el ser humano se halla tanto en continuidad como en distancia cualitativa con el resto de las especies de la biosfera, pues, aunque es una especie más, sus características específicas lo sitúan en un nivel de diferencia cualitativa respecto a las especies de las que ha emergido. De este modo, pretendo llegar a concluir que el ser humano, a diferencia del resto de las especies vivas, constituye una irrepetible y compleja unidad 
bio-cultural y psico-orgánica, dotado de autoconciencia, autonomía, lenguaje, pensamiento complejo, libertad, capacidad ética, apertura a la pregunta por el sentido de su vida y del conjunto del cosmos, $y$, por eso mismo, en apertura a la pregunta por el fundamento de la realidad, es decir, al ámbito de los Absoluto.

\section{La comparación hombre-animal: dos enfoques complementarios (científico y filosófico), y cuatro ámbitos de comparación}

\subsection{Ciencia y filosofía: dos modos complementarios de acercarse a la realidad y al ser humano}

Antes de introducirnos en el ejercicio comparativo de los diversos elementos que diferencian a los seres humanos del resto de los demás animales, tenemos que ser conscientes de que hemos de conjugar correctamente dos modos de comprensión y de acercamiento a la realidad: el científico y el filosófico. Cuando nos planteamos la comparación hombre-animal, la discusión se suele reducir con frecuencia a la tarea de presentar los más diversos datos e investigaciones que continuamente están aportando el amplio abanico de las ciencias, tanto naturales como humanas. Pero el resultado de tales disputas no suele traer demasiada claridad al problema, porque no es suficiente apelar a los datos científicos para dilucidar esta compleja cuestión, necesitada ante todo de un adecuado y correcto planteamiento. De entrada hay que decir que los datos científicos, en sí mismos, no significan nada para elucidar la distinción entre hombres y animales. Son mera constatación de hechos, que, por otro lado, nunca van solos, sino acompañados de los inevitables y necesarios aprioris y prejuicios (presupuestos filosóficos) desde los que sistematizamos los datos científicos para conformar una teoría científica unificadora. .

La realidad, y el ser humano dentro de ella, tiene dos dimensiones claramente diferenciadas: la dimensión fáctica y la del sentido o significado de la misma. Es decir, siguiendo la diferenciación de $M$. Foucault, no es suficiente para dar cuenta de la realidad humana detenernos en investigar su funcionamiento, en todos sus aspectos (biológico-genético, fisiológico, psicológico, conductual, etc.), sino que se necesita además preguntarnos y tratar de dilucidar su sentido, su dimensión trascendental. Al primer nivel se dedican las ciencias, las antropologías científicas, y al segundo, la filosofía, o mejor, las filosofías, con sus diferentes modelos antropológicos ${ }^{9}$. La negación o el olvido de esta distinción suele tener consecuencias nefastas, en la medida en que supone en ambos 
casos apoyarse, sin tener suficiente consciencia de ello, en una filosofía implícita, el naturalismo filosófico o materialismo reduccionista. Con lo cual, además de presentarse las afirmaciones filosóficas como si fueran científicas, que no lo son, constituyen y representan una mala filosofía. Es decir, no es lo mismo afirmar que el ser humano está configurado, desde los diferentes ámbitos científicos que queramos, por los rasgos y las características que sean (tarea específica de las ciencias), que afirmar que su ser y su sentido se limita a esos simples datos. Esa afirmación, además de no ser científica (no se puede demostrar ni falsar), es equivocada, por insuficiente.

Un ejemplo reciente de este modo tan reduccionista de ver las cosas es el libro de aforismos del profesor español J. Wagesberg, con este título tan significativo: A más cómo, menos por qué ${ }^{10}$. Lo que parece indicarnos es que cuanto más consigan las ciencias descubrirnos cómo funcionan los diferentes ámbitos de la realidad (ámbito del cómo), menos espacio quedará para las preguntas de por qué, de sentido. Por el contrario, habría que responder más bien, que cuantas más respuestas hallemos a los "cómos", más espacio y ocasiones se abrirán a los "porqués"; o dicho de otra forma: ni mil respuestas a los cómos podrán acallar un porqué, puesto que son dos niveles diferentes, paralelos e inevitables. Como dice significativamente $X$. Zubiri, la realidad nos da que pensar, y nos empuja a la pregunta por el fundamento, por las cuestiones últimas ${ }^{11}$. Muchas de las importantes discrepancias a cerca del ser humano y de la realidad son consecuencia de la no correcta distinción de planos entre la ciencia y la filosofía, incurriendo en sucesivos reduccionismos: metodológico, epistemológico, ontológico y antropológico, absolutizando una sola dimensión (la científica) y quedándose con una parte de la realidad como representativa del todo.

Volveremos más adelante sobre este asunto, puesto que nos va a ir apareciendo en cada uno de los diversos ámbitos de comparación entre hombres y animales que vamos a analizar a continuación.

\subsection{Cuatro ámbitos de comparación}

Se trata de preguntarnos si la diferencia entre hombre y el resto de los animales es sólo cuantitativa o posee un rango cualitativo. Esta comparación podría hacerse en múltiples aspectos, pero se suele considerar que los más importantes y significativos son los cuatro siguientes ${ }^{12}$ :

- El bioquímico y genético;

- El anatómico-morfológico;

- El embriológico, desde el especial puesto del hombre en el proceso embriológico u ontogenético;

- El referente a la estructura comportamental. 


\section{$\begin{array}{ll}\overline{\bar{D}} & \text { 2.2.1. El ámbito bioquímico y } \\ \text { genético } & \end{array}$}

Las investigaciones recientes sobre el genoma de las diferentes especies vivas van mostrándonos las diferencias y parecidos entre la estructura genética del ser humano y del resto de las especies animales.

Si comparamos nuestra composición bioquímica y la del resto de las especies, advertimos que no nos diferenciamos en nada respecto de los demás seres vivos. Estamos hechos de la misma pasta bioquímica. No poseemos ninguna sustancia química específica, ni carecemos de ninguna de las que se dan en las otras especies.

Además, la sustancia bioquímica está organizada de similar forma que en el resto de los seres vivos. Nuestra estructura genética se halla codificada en el ADN hereditario, que se organiza y reproduce de la forma común a todas las especies vivas, siguiendo lo que se ha solido denominar (aunque hoy día se está poniendo en cuestión) la ley fundamental de la genética: ADN-ARNProteínas. La relación entre estos tres componentes se orienta siempre en esta dirección: de izquierda a derecha, no dándose en la relación de esta estructura genética la denominada lógica lamarckiana de transmisión de los caracteres adquiridos. Esto es lo que hace que los científicos defiendan la unidad evolutiva de la vida. La vida apareció sólo una vez, y de ese salto cualitativo descendemos todos los seres vivos.

Nuestro ADN está configurado, al igual que en las demás especies, por una estructura de doble hélice (descubierta por Watson y Crick) ${ }^{14}$, unida por cuatro bases nitrogenadas (Adenina-Guanina, Citosina-Timina, esta última transformada en Uracilo cuando se traduce el ADN en ARN). No es necesario que nos detengamos aquí en explicitar las concreciones de los diferentes procesos que se dan en la reproducción genética de los seres vivos ${ }^{15}$. Pero sí es importante que veamos algunos aspectos diferenciadores en este aspecto entre nuestra especie y las más cercanas a nosotros. En la conformación de las proteínas, siguiendo esa ley fundamental de la genética, se van construyendo cadenas de aminoácidos, advirtiéndose que en la composición, por ejemplo, de las cadenas alfa y beta que forman la hemoglobina A, la diferencia entre el hombre y el chimpancé en la composición de los 141 aminoácidos de la cadena alfa y en los 146 de la cadena beta es cero, no hay ninguna diferencia. En cambio, entre el hombre y el gorila, hay un aminoácido de diferencia en cada una de las cadenas, y de modo progresivo se van agrandando las diferencias en relación a especies que se hallan más lejanas a nosotros en el proceso evolutivo ${ }^{16}$. Y también podríamos hacer referencia a otras pequeñas diferencias en relación a nuestras enzimas y proteínas, para 
llegar a la misma conclusión: los parecidos son mínimos, aumentándose a medida que las especies se hallan más alejadas en el árbol de la evolución.

Una diferencia clave está en el componente cromosómico de nuestra herencia genética. Mientras la especie humana está dotada de 23 pares de cromosomas, los grandes simios poseen 24 pares. Parece una pequeña diferencia, y todavía se diluye más si tenemos en cuenta que "los cromosomas de ambos grupos son muy semejantes entre sí, y no sólo uno a uno sino banda a banda, excepto en lo que respecta a algunas mutaciones cromosómicas, como la fusión de dos de los cromosomas de los antropoides en uno del hombre ${ }^{\prime 17}$.

Las investigaciones sobre el genoma humano han servido para profundizar en nuestros parecidos con el resto de las especies vivas. En el año 2001 se hizo público el primer borrador del genoma humano, completándose en 2003 su secuenciación, con una fiabilidad casi total. Dos años más tarde, en 2005, se publicaba también el primer borrador del genoma del chimpancé. Ya en 1995 se había secuenciado el Micoplasma genitalium (un micoplasma es el organismo más pequeño que puede tener un organismo independiente) ${ }^{18}$, que posee sólo 470 genes y $580 \mathrm{kpb}{ }^{19}$. En años posteriores se han ido secuenciando los genomas de otras muchas espe- cies vivas, advirtiéndose una correlación entre el número de genes y de miles de pares de bases y la complejidad de cada especie viva.

Estas investigaciones nos han mostrado que la similitud genómica entre el homo sapiens y el chimpancé ${ }^{20}$ es muy grande, llegando al 99 $\%$ (si nos referimos a la "secuencia", esto es, el orden de los alrededor de 3.200 millones de pares de bases o "letras químicas" que parece componen el conjunto de la estructura del $A D N{ }^{21}$ ), siendo esto indicativo del relativamente corto espacio de tiempo en que ambas especies se habrían desgajado de la especie común anterior: se calcula entre 5 y 7 millones de años. El Homo sapiens posee $3.200 \mathrm{Mpb}$ y cerca de 25.000 genes, resultando sorpresiva esta cifra tan baja. Se especulaba anteriormente con que poseyera unos 100.000 genes, $y$ más adelante se rebajó la cifra a 30.000 , pero las investigaciones más recientes han dejado la cifra en esos 25.000 (y algunos la rebajan incluso a 23.000).

Estos avances tan espectaculares están produciendo no sólo un incremento de nuestros conocimientos, sino también nos están obligando a corregir algunos de los denominados dogmas genéticos, entre los que se encuentran, por ejemplo, los conceptos de genoma y de gen. Genoma significa en la actualidad tanto "el mapa físico de la localización de los genes en los 
cromosomas", como "la secuencia completa de pares de bases del ADN"; es decir, puede ser entendido como "material genético" o como "información genética y conjunto de genes" característico de una especie determinada ${ }^{22}$. En relación con el concepto de gen, acuñado por W. Johannsen en 1909 para denominar a los factores hereditarios investigados por G. Mendel, en la actualidad tiene una amplia pluralidad de significados, de modo que "la palabra gen no significa lo mismo para un genetista clásico, que para un genetista de poblaciones, que para un genetista del desarrollo, que para un biólogo molecular. Incluso para un genetista molecular se presentan diferentes definiciones de gen" ${ }^{23}$. Pero, en definitiva, se puede reducir esa pluralidad semántica del gen a dos aspectos bien concretos: "el gen como última unidad de mutación y recombinación" y "el gen como unidad de información" ${ }^{24}$. Esta segunda acepción del gen es el fundamento en el que se apoya el denominado dogma central de la genética, en la medida en que se daba por hecho que un gen (como unidad del ADN que se convertía en $A R N$ ) daba lugar a una proteína, que a su vez realizaba una función (una enzima).

Pero este dogma se ha puesto en cuestión en la actualidad, en la medida en que se advierte que se dan fenómenos como la poligenia (varios genes distintos pueden influir en la expresión de un mismo rasgo o comportamiento) y la pleiotropía (un solo gen puede influir sobre el desarrollo de varios rasgos físicos o comportamientos) ${ }^{25}$. Por tanto, aunque por un lado la genética sabe cada vez más acerca de la estructura genómica, ese mayor conocimiento le ha mostrado su inesperada complejidad, en la medida en que no hay una relación directa entre unidad genómica y unidad fenotípica, y además no todos los genes tienen expresión funcional ni sirven como información para la configuración fenotípica del organismo vivo. Dentro del ADN se dan segmentos de gen que poseen información y acaban representados en una proteína (son los exones), y otros segmentos que aparentemente no tienen utilidad de cara a la conformación de proteínas (intrones), interrumpiendo la secuencia codificadora. Hay, por tanto, una parte del genoma,que se ha denominado por ello genes basura, o ADN intragénico (viene a representar nada menos que el $62,5 \%$ del contenido total del genoma), que "no conocemos por ahora cuál sea la función fisiológica de esta gran cantidad de ADN, cerca de dos tercios a los que no se les ve, por ahora, que contengan ninguna misión en el genoma o en el desarrollo del organismo. Puede ser que esta porción notable del genoma tenga una función tan sutil que al presente se nos escape" ${ }^{26}$.

Por tanto, frente a la creencia ingenua de la genética clásica, que consideraba que en el conjunto del 
ADN estaba ya encerrada toda la información que se necesitaba para conformar el fenotipo morfológico y conductual del ser vivo, en la actualidad se advierte que esa traducción del genoma al fenotipo es mucho más complicada y abierta de lo que se creía. Y no sólo por los fenómenos ya indicados de la poligenia y la pleiotropía, lo que supone que un solo gen puede originar varias proteínas, sino también porque cada proteína puede llevar a cabo funciones diferentes. Por eso, en la actualidad va teniendo cada vez más importancia, junto al genoma, el concepto de proteoma, "conjunto de proteínas que especifican la naturaleza de todas las reacciones bioquímicas que una célula puede llevar a cabo en un momento determinado. Así como el genoma es el mismo para todas las células diploides, el proteoma puede variar según el momento de la vida celular" 27.

Como puede verse, la complejidad del camino a seguir de un rasgo genómico, a través de la traducción en el abanico proteínico, hasta que llega a expresarse en los diferentes rasgos del fenotipo, es un camino largo y complejo que no tiene una única ruta, sino varias posibles, en función de factores aleatorios que se dan en los diversos recovecos de ese intrincado camino.

Las conclusiones que de todo lo dicho podemos sacar son varias:
1) La ciencia todavía sabe poco y anda a tientas en su interesante trabajo de exploración de nuestra estructura genética y de los procesos a través de los cuales se expresa. El trayecto que va del genoma al fenotipo, campo de estudio de la biología molecular y de la biología del desarrollo, está lleno de interrogantes y de vacíos sin aclarar. Por eso, como hemos visto, cada vez está más clara la importancia de ciencias como la biología del desarrollo, o genética del desarrollo, y la embriología, que estudian los fenómenos del proceso de traducción del material informativo del genoma hasta su expresión fenotípica, tanto en sus aspectos físicos y morfológicos como también conductuales, en la medida en que la genómica ya no se reduce al análisis de la secuencia de cada uno de los genes, sino que abarca también la combinación con otros elementos que los encienden, los frenan o los aceleran en su función. Por eso, si el ámbito del genoma es complicado, todavía lo es más el del proteoma.

2) La mera descripción de los datos científicos, como ya dejamos dicho, es insuficiente para la comprensión de lo humano. El punto de vista científico no nos indica más que el funcionamiento de la máquina corpórea 


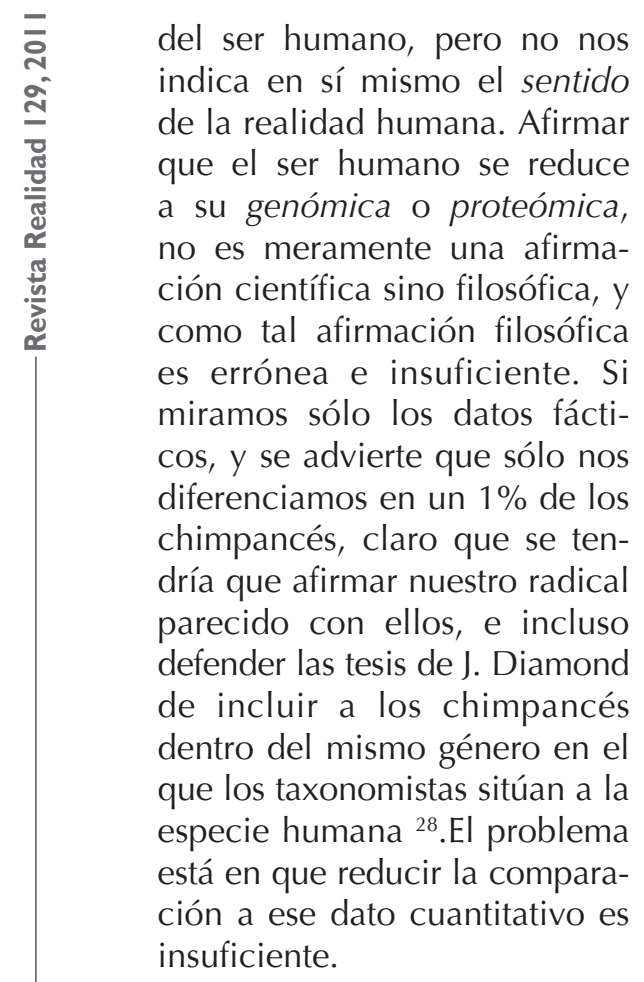

3) La complejidad que nos manifiesta el proceso de expresión del genoma en el fenotipo, es una mostración de que la naturaleza con pocos cambios es capaz de generar realidades extraordinariamente diferentes. Es como los radios de una circunferencia: en el inicio están cercanos, pero a medida que se prolongan crece su separación y diferencia. Es decir, en el caso del ser humano se advierte que unas pequeñas diferencias cuantitativas son la causa de posteriores diferencias de gran significado, como son su cerebro, el lenguaje, el bipedismo permanente, la mano prensil, $y$ en definitiva una conducta cualitativamente diferente.

4) Y aquí está la conclusión más significativa: lo fundamental no está en comparar las diferencias en el punto de origen, sino en sus expresiones morfológicas y conductuales. Y este punto de vista lo que nos muestra es que esas pequeñas diferencias son más significativas de lo que parecen, puesto que son la causa de un modo de ser y de actuar que sí representa una clara diferencia cualitativa, como vamos a tener ocasión de comprobar en otros aspectos que vamos a analizar a continuación. Todo esto nos hace ver, como indica J. Ruffié, que la naturaleza innova poco $^{29}$, y con pocos cambios en lo genético es capaz de dar de sí realidades fenotípicas muy diferentes entre sí.

De ahí que podamos concluir que lo que nos diferencia con los animales más cercanos a nosotros no es sólo esa pequeña proporción de genes, sino también el itinerario que siguen hasta su expresión fenotípica, tanto morfológica como conductual. De ello tenemos que concluir que la esencia o naturaleza del ser humano no se halla encerrada exclusivamente en su ADN, como si fuera la potencia aristotélica que se expresa y se convierte en acto en el fenotipo, sino que el desarrollo del genoma desde el ADN hasta su 
expresión fenotípica es más complejo y decisivo en la configuración de un ser humano de lo que hasta ahora creíamos. Aunque todavía no sepamos del todo identificar el conjunto de pasos que se dan en ese complejo y extraordinario proceso.

\subsubsection{El punto de vista anatómico- morfológico ${ }^{30}$}

Los parecidos anatómicos entre nuestra especie y los chimpancés son muy claros y abundantes. "El cuerpo humano, dice F. J. Ayala, está construido con arreglo al mismo plan general que los cuerpos de otros animales, siendo más semejante al de los antropoides, los primates, los mamíferos y los vertebrados, por este orden descendente. La semejanza y correspondencia, hueso a hueso, entre los esqueletos de un antropoide y un ser humano son impresionantes. Algunos de los huesos son tan semejantes entre sí que resulta difícil identificar la especie de procedencia" ${ }^{31}$.

Como es evidente, los parecidos con los antropoides o simios superiores es mucho mayor que con otros animales más distantes en la cadena evolutiva. Así, son dignos de señalarse estos parecidos entre los humanos y los chimpancés: la visión estereoscópica y policromática, la inmovilidad de las orejas, la reducción del olfato, la pérdida de pelos táctiles, la existencia de un tiempo menstrual y ausencia de un período estacional de cría, producción de una sola cría por parto como regla común, gran cuidado maternal y dominancia de los machos adultos sobre las hembras e individuos jóvenes ${ }^{32}$. Pero hemos introducido ya en esta lista elementos conductuales, no sólo aspectos morfológicos y fisiológicos.

Ahora bien, a pesar de estas grandes similitudes, también se dan varias diferencias significativas que las vamos a sintetizar en cuatro:

a) el bipedismo, con todos los cambios morfológicos que supuso de cara a la conformación de los huesos de las extremidades inferiores y la cadera, así como de la columna vertebral, orientadas a poder acomodarse correctamente a caminar erguido de forma constante ${ }^{33}$;

b) la mano prensil, con el dedo gordo oponible a los otros cuatro, que es consecuencia de cambiar su función de extremidad delantera para caminar, así como también para asirse a las ramas de los árboles, a instrumento para manipular objetos pequeños que exigen gran precisión de movimientos, así como para manejar herramientas y construirlas ${ }^{34}$;

c) la progresiva cerebralización y ampliación de la cavidad craneana ${ }^{35}$. Esta diferencia es un punto clave, y no se limita a la mera cantidad de la masa 


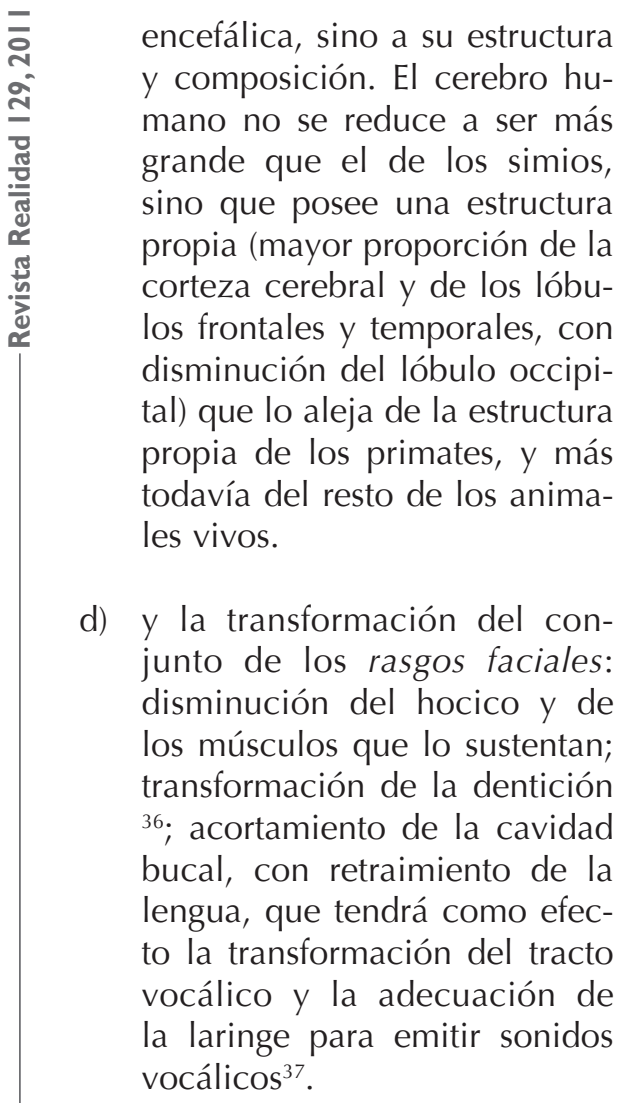

¿Qué conclusiones podemos sacar de estos datos? ¿Son significativos para defender una diferencia cualitativa entre los humanos y demás animales, o no da más que para una mera diferencia cuantitativa?

De nuevo tenemos que concluir de forma similar que en el apartado anterior:

-No es suficiente la mera constatación de datos y de hechos, puesto que podrá decirse, con razón, que la diferencia en lo anató- mico-morfológico entre la especie humana y los diferentes primates es menor que la que hay entre éstos y la inmensa mayoría de las especies vivas.

- Ahora bien, para que la comparación sea significativa, tenemos que hacer referencia a la función o soporte que estas diferencias indicadas suponen de cara a comportamientos tan importantes y específicoscomo pensar (cerebro), hablar (cerebro-laringe), y demás comportamientos inteligentes y libres propios de nuestra especie. Por tanto, si tenemos en cuenta este aspecto, y no podemos dejar de hacerlo, se advierte con claridad que aspectos anatómicos como el cerebro y el conjunto del aparato fonador, por lo que suponen de soporte fisiológico de funciones tan importantes como pensar, hablar y actuar libre y responsablemente, constituyen elementos suficientemente significativos como para servir de base a un criterio de diferenciación cualitativa, y no sólo cuantitativa.

\subsubsection{La comparación desde el pro- ceso embriológico}

Un tercer punto de comparación, que resulta muy significativo, como vamos a ver, es el referente al proceso de ontogénesis, del que se ocupa la embriología. Si en la comparación morfológica veíamos el enorme parecido entre el hombre y las especies más cercanas, lo mismo ocurre en las diferentes 
fases del proceso embriológico, según nos indica la embriología comparada ${ }^{38}$. Los parecidos son muy significativos, atravesando todo el proceso las mismas tres etapas fundamentales: cigoto (tres primeras semanas), embrión (hasta el final de la octava semana) y feto (hasta el nacimiento).

Resulta significativo resaltar que en este proceso embriológico, se da una cierta repetición de la historia filogenética, resultando de algún modo certera la teoría de Haeckel de que la ontogénesis repite y resume de cierta medida la filogénesis. De este modo, el cuerpo humano en su desarrollo intrauterino viene a ser una recapitulación ontogenética de la filogénesis de su propio género y de toda la evolución.

Prueba de ello es que, en el proceso de desarrollo de la forma total del embrión, van apareciendo de forma más o menos transitoria estructuras embrionales y fetales que hacen recordar formas de especies que se hallan situadas en el proceso evolutivo anterior, desde las amebas hasta los primates. Veamos algunos de estos fenómenos:

- La pasajera aparición de restos de branquias, recuerdo de nuestros antepasados los peces, y luego los anfibios;

-El paulatino cambio de posición de los ojos, desde una postura lateral (es la posición de los ojos en los peces, lagartos, ratones, cabaIlos, etc.) irán evolucionando hasta situarse delante de la cara, mirando hacia el frente, para adquirir una mirada estereoscópica;

-El esbozo de la cola (entre 8 y 9 segmentos vertebrales), que luego se transformará en el cóccix. Lo posee el embrión de alrededor de seis semanas, y puede alcanzar una longitud entre 14 y 16 mms. En algunos casos especiales, no se supera esta fase y nacen de vez en cuando niños con cola ${ }^{39}$;

— La aparición del lanugo fetal, que se da entre el séptimo y noveno mes, y luego desaparece, recordándonos el fuerte sistema piloso de los mamíferos, y nos recuerda nuestra condición de "mono desnudo" (D. Morris);

- La oclusión parpebral del embrión: hacia el tercer mes, los párpados del embrión están cerrados y soldados, y así permanecen hasta el séptimo mes. Teniendo en cuenta este rasgo, se suelen dividir las especies animales en dos clases: nidícolas, predispuestas a alargar su fase de maduración en el nido, y nacen con los párpados cerrados (es el caso del ratón, conejo, gato, perro y los monos inferiores), y nidífugas, orientados a una independencia más rápida, naciendo con los ojos abiertos (ternero, caballo, foca, elefante). El ser humano participa de un aspecto de ambos grupos: por un lado, nace con los párpados 
abiertos, como los nidífugas, pero en cambio es la especie que alarga más su permanencia en el nido materno, dado su extrema invalidez, uno de los rasgos específicos de nuestra especie.

Podíamos hacer referencia a otros rasgos menores, que nos recuerdan la persistencia en el proceso embriológico de otros aspectos morfológicos de las especies anteriores, pero con lo dicho es más que suficiente para probar la tesis del resumen en el proceso ontogenético de las fases del proceso filogenético. Con lo dicho, estaríamos apuntalando el aspecto de los parecidos. Pero lo interesante es que en este proceso embriológico es donde se empiezan a ver mayores diferencias con las demás especies, apuntándose así el especial puesto del hombre en el proceso ontogenético general. ¿Dónde se hallarían las diferencias?

El proceso embriológico de todas las especies vivas sigue una lógica básica: los individuos de cada especie nacen en el momento en el que se ha conseguido, por parte del feto, de la madurez correspondiente, la propia de la especie, para poder luego desenvolverse con éxito en la tarea fundamental de adaptarse al entorno ambiental, a su nicho ecológico. Y, en función de esa lógica, durará más o menos el proceso de gestación y ontogénesis. $Y$, aunque cada animal sigue una lógica propia, podemos decir que todas las especies tienen la capacidad de traer al mundo individuos que pueden desenvolverse con relativa rapidez e independencia en la lucha por la supervivencia.

En cambio, en el ser humano se ha roto esta lógica básica, en la medida en que el proceso embriológico se ha detenido, y el recién nacido se parece al "feto de un mono". "Así, según Y. Coppens, en el estado adulto seríamos bastante semejantes a fetos de mono. En todo caso, más próximos al feto del mono que al mono mismo. Esta persistencia de caracteres juveniles o fetales es lo que se Ilama neotenia" $^{40}$. La especie humana es, pues, una especie que ha ralentizado su desarrollo, y nace antes de tiempo, de forma prematura. Formamos una especie de prematuros, de inmaduros biológicos. Necesitaríamos estar doce meses más en el útero materno (21 meses debería durar nuestra gestación) para poder nacer con la madurez biológica y comportamental con la que nace el resto de las especies vivas, según Portmann ${ }^{41}$.

Según los antropólogos, en la adquisición de este rasgo se ha dado un proceso de coevolución con otros elementos fundamentales de la especie humana: la postura erguida, que estrechó las caderas y el canal pélvico, hecho fundamental para las mujeres por su relación de cara al parto, lo que favoreció en el proceso evolutivo la tendencia a acortar el tiempo de gestación, 
para poder dar a luz hijos con una capacidad craneana adecuada para poder atravesar el canal pélvico y llegar a nacer, dejando la tarea de ampliar la capacidad cerebral a los años posteriores a su nacimiento. De ahí que el nacimiento prematuro, que supone una mayor dependencia de los padres y de su entorno cultural, se tiene que conjugar y completar con un proceso de maduración y de dependencia más largo. Este factor, que representa la cara negativa de la deficiencia y de mayor dependencia, conlleva la ventaja de dotar al recién nacido de una mayor plasticidad, que redunda en su educación y maduración.

Son claves en este cometido las primeras fases posteriores al nacimiento, el denominado "año extrauterino del embrión", en la medida en que en esa fase primera ser producen procesos como la maduración de la vista y de los sentidos en general, la capacidad de caminar, la maduración de la mano prensil, una primera e importante fase de cerebralización (el recién nacido nace con el número completo de neuronas, unos cien mil millones, pero la maduración cerebral se va produciendo y completando después, y sobre todo, a través del logro de las innumerables conexiones sinápticas que serán el soporte cerebral de todas las habilidades conductuales), y el empezar a balbucear un lenguaje elemental.
Por tanto, la deficiencia biológica de los seres humanos (A. Gehlen) le impele a ser necesariamente un animal cultural, a ser moldeado por el útero cultural con objeto de suplir esas deficiencias biológicas. Y en este proceso de maduración y de educación cultural, intervienen tanto las capacidades innatas recibidas en su dotación genética como su capacidad de imitar y aprender de los demás compañeros de especie.

Si evaluamos en su globalidad este rasgo comparativo, vemos que ya las diferencias con los primates y demás especies animales se van agrandando. En los dos aspectos anteriores (genética y morfología), las diferencias eran ciertas y evidentes, pero quizás no tan significativas y explícitas como esta curiosa y específica situación de nuestra especie en el proceso ontogenético. Pero tenemos que volver a insistir en que, ateniéndonos exclusivamente a los datos científicos, son plausibles y legítimas las dos posturas en conflicto:

- La que interpreta las diferencias como meramente cuantitativas, se puede apoyar en el hecho de que hay más parecidos entre el hombre y los simios, que entre éstos y los animales más elementales; y más todavía si tenemos en cuenta que también en los chimpancés podemos advertir una cierta inmadurez y no fijación total, en clave de instintos, de sus pautas comportamen- 
tales. Sus presupuestos reduccionistas no le permite a esta postura conceder más;

-Y la que ve ya aquí una diferencia radical y cualitativa, que se completará en el apartado siguiente, cuando hagamos referencia a la estructura comportamental específica del ser humano, que se sustenta precisamente en esta deficiencia biológica, siendo su cara positiva. Se advierte, pues, desde este punto de vista, tanto la continuidad como también la ruptura cualitativa entre nuestra especie y el resto de las especies de la biosfera. Los seres humanos repetimos las mismas fases del proceso embriológico, pero de otra manera, deteniéndose el proceso de maduración para empujarnos al mundo antes de tiempo: hemos dicho ya que parecemos el feto de un mono. Así, a diferencia de la tesis de los estratos de M. Scheler, que parte de situar al ser humano en un peldaño más arriba del proceso de maduración evolutiva (acentuando la continuidad), la postura de Gehlen hace romper esta lógica, viendo al ser humano no como un animal más perfecto y maduro, sino como un animal diferente, que sigue otra ley y estrategia de maduración: suple con el aporte de aprendizaje cultural la deficiencia biológica. No hay, pues, aquí una superación desde una fase o escalón que subsumiría evolutivamente los anteriores, sino que rompe y supera esa lógica a través de un salto cualitativo. No persigue tanto adaptarse al ambien- te, aunque fuera con una fórmula más perfecta (postura pasiva propia de las otras especies vivas), sino que adopta una postura activa y transformadora, por cuanto tiene que adaptar obligatoriamente el entorno a sus necesidades. De nuevo vemos que se ha invertido la lógica de la adaptación: el animal tiene ambiente, el hombre tiene mundo, construido artificialmente.

Este aspecto de inmadurez supone ya la base fisiológica de la específica estructura comportamental del ser humano, por lo que no necesitamos detenernos aquí y pasamos a la siguiente faceta comparativa.

\subsection{Comparación desde la estruc- tura comportamental}

Si en el ámbito de lo genético y morfológico, e incluso en el terreno del desarrollo embriológico, podemos apelar a unos datos más o menos objetivos, que necesitan posteriormente su interpretación, en el terreno del análisis del comportamiento o estructura comportamental el esfuerzo interpretativo se hace necesario casi desde el primer momento, porque casi no existen meros datos objetivos de comparación. Todos dependen ya de una mirada interpretadora, deudora de un trasfondo antropológico y cosmovisional. Pero, al mismo tiempo, constituye este aspecto el punto más importante y decisivo para el tema que estamos estudiando aquí, 
en la medida en que el punto donde se diferencian más claramente hombre y animales es precisamente en su estructura comportamental.

¿En qué se diferencia el comportamiento de los animales del de los humanos? ¿Podemos establecer una división entre los humanos y el resto de los animales, o nuestro comportamiento es sólo un poco más inteligente y complejo que el de los primates, habiendo entre éstos y los animales anteriores una diferencia tan grande y significativa como la que hay entre los primates y los humanos?

El empeño por estudiar el comportamiento de los animales se puede encontrar ya en la época de Aristóteles. Pero el estudio científico se comenzó a realizar a partir de las teorías de Darwin. Es a partir de entonces cuando comienzan a darse dos planteamientos contrarios en la interpretación de los comportamientos animales: los innatistas y los ambientalistas ${ }^{42}$. Los primeros intentos serios sobre el comportamiento animal dan lugar a la aparición de la etología, de la mano de tres científicos europeos, Konrad Lorenz, Karl von Frisch y Niko Tinbergen, que recibieron conjuntamente el Premio Nobel en 1973. La etología de estos autores insiste en la dimensión innata de la conducta animal, pero entienden que el componente innato hay que conjugarlo y complementarlo con el aprendizaje ${ }^{43}$. En cambio, el conductismo norteamericano, de la mano de Watson y Skinner, defendía que la conducta animal y humana era fruto exclusivo de las influencias ambientales.

La mayoría de los estudiosos del comportamiento, tanto animal como humano, entienden que es el resultado de compaginar lo innato con lo aprendido, aunque el problema radica en cómo conjugar ambos componentes. Pero sigue habiendo partidarios de las dos posturas extremas: el innatismo y el ambientalismo. Referidas al comportamiento humano, ambas posturas defienden tesis deterministas, aunque sus posturas suelan ser muy ambiguas en este punto, como vamos a ver. Nos detendremos, en primer lugar, en analizar los planteamientos de la so- $^{-}$ ciobiología (determinismo genético) y del conductismo (determinismo ambiental), para luego ver referirnos a las posturas que conjugan lo innato y lo aprendido.

\subsubsection{Las tesis deterministas}

a) El determinismo genético de la sociobiología ${ }^{44}$

La sociobiología, nacida en los EE.UU. a partir de la obra de E. O. Wilson y otros autores, pretende explicar tanto el comportamiento animal como el humano desde las leyes centrales de la genética. Para estos autores, el sujeto de la evolución no es ni la especie (como defendía K. Lorenz) ni los indivi- 
duos, sino los genes. El objetivo que persiguen es la supervivencia y estar representados del modo más abundante en las generaciones siguientes. En definitiva, la ley que los empuja es la del egoísmo genético (el gen egoísta, R. Dawkins). Y con esta lógica pretenden explicar toda la conducta de los seres vivos, sintetizada en cuatro ámbitos fundamentales: la agresividad, la relación entre sexos, la relación paternofilial, y las conductas "altruistas" 45 .

Es importante advertir que no todos los sociobiólogos defienden la extrapolación de estas pautas de conducta al ámbito humano. Mientras la corriente norteamericana defendería tal extrapolación, la inglesa, con Dawkins a la cabeza, sería partidaria de separar ambos terrenos.

En definitiva, para los sociobiólogos, la cultura humana no es más que un componente más nacido por evolución y controlado directamente por los genes, $y$, por tanto, tiene que estar al servicio de los genes y de su lógica de egoísmo genético. Y cuando decimos cultura estamos hablando de todos sus componentes, también la ética y la religión. La ética sería, para Wilson, una estrategia más de los genes al servicio de la supervivencia, al igual que a otras especies les ha dotado de alas, branquias o garras para sobrevivir en un nicho ecológico determinado ${ }^{46}$.

Frente a los evolucionistas clásicos, que pretendían deducir las normas éticas de la lógica evolucionista, cayendo de ese modo en la falacia naturalista, Wilson pretende escapar a esa falacia, pero creemos que sin conseguirlo. Así, cuando afirma que "el comportamiento humano - con las capacidades de respuesta emocional que lo impulsan y lo guían- es la técnica indirecta por la cual el material genético humano ha sido, y será, mantenido intacto. La moralidad no tiene otra función última demostrable ${ }^{\prime 47}$. Pero, como indica F. J. Ayala, es una afirmación incorrecta tanto si se refiere a la capacidad ética (puesto que los humanos somos éticos por naturaleza, y no porque esto sirva a la eficacia genética) o a los contenidos éticos. Si se refiere a lo segundo, sería defender la falacia naturalista.

Las críticas a la sociobiología suelen venir de tres ámbitos diferentes. Desde el estrictamente científico, los etólogos tienen que comprobar si las tesis sociobiológicas se sostienen, referidas al campo exclusivamente del comportamiento animal. Esto queda en manos de los etólogos, y no todos están de acuerdo con las tesis sociobiológicas, puesto que si en muchos campos del comportamiento animal parecen comprobarse sus tesis, no ocurre así en todos los casos. Por ejemplo, en el terreno del altruismo, puesto que no siempre las tesis egoístas se cumplen y son más eficaces, ni tampoco está claro que el gen sea el sujeto de la evolución ${ }^{48}$. Otro campo de crítica se refiere a la legitimidad o 
no de extrapolar las tesis biológicas al área del comportamiento humano, puesto que ello supondría negar la libertad humana, y la autonomía de la cultura, con todos sus diferentes ámbitos; así como no poder escapar a la ambigüedad consistente en defender el determinismo y mantener planteamientos éticos (Wilson, en "Sobre la naturaleza humana $\left.^{\prime \prime}\right)^{49}$. Y en tercer lugar, mirando el problema desde la sociología del conocimiento, se ha acusado a los sociobiólogos de un claro sesgo ideológico en sus planteamientos ${ }^{50}$.

\section{b) El determinismo ambiental del conductismo}

Se trata de un enemigo que podemos considerar ya superado en su globalidad, desde mitades del siglo XX. Pero nos referimos a él como un modo clásico y ejemplar de entender la condición humana. Frente a la postura sociobiológica, que sitúa el motor de nuestra conducta en los genes, con su lógica egoísta, el conductismo de Watson y de Skinner da por hecho que somos hechura de nuestro entorno. La estructura comportamental está configurada por la relación directa estímulo-respuesta (E-R), por más que este sencillo esquema se pueda completar y complejificar por la retroalimentación, según Skinner, de los refuerzos (positivos y negativos), que suponen la diversa forma de responder el ambiente (natural y humano) a nuestra respuesta al mismo.
Hoy día son pocos, si es que hay alguno, que defienda el conductismo, como postura antropológica determinista, en toda su crudeza, tal y como se dio en la primera mitad del siglo XX en los EE.UU. Sus planteamientos perdieron apoyos como consecuencia del progresivo triunfo de las tesis etológicas, que reivindicaban el elemento innato y genético en la conducta, y de las ciencias cognitivistas, que supusieron el retorno del concepto de lo mental.

Así, si es verdad que las circunstancias del ambiente nos influyen, en la medida que sea, sin embargo no nos determinan. Por otro lado, se da en el conductismo, sobre todo en el de Skinner, la misma ambigüedad que en sociobiólogo Wilson a la hora de querer conjugar determinismo y planteamientos éticos (como en su utopía Walden dos), pudiendo advertirse una doble concepción del ser humano: por un lado, lo que podríamos denominar el hombre masa, sobre el que teoriza Skinner, hombre que, por hallarse dominado por el ambiente, necesita un salvador que le libere de su dominación y le trasplante a un nuevo paraíso terrenal ( $\mathrm{Wal}$ den dos), y por el otro, el hombre élite, representado por el propio Skinner y cualquier ingeniero de la conducta, que es consciente de esa dominación del ambiente, no está sometido a ella, quiere liberar al hombre masa, y construye un artefacto social para liberarlo. Si no se 
hace esta distinción antropológica, difícilmente se puede aceptar como coherente la teoría conductista.

\subsubsection{Entre la genética y el ambiente}

Los estudios sobre el comportamiento animal y humano nos indican que, tanto en el caso de los animales como en el ser humano, la comportamiento tiene componentes innatos y aprendidos, por lo que hay que superar determinados mitos del pasado, como, en primer lugar, pensar que el comportamiento humano es sólo fruto del aprendizaje, como defiende la denominada tesis de la tabla rasa desde J. Locke; o, en segundo lugar, pensar que el comportamiento animal es fruto exclusivo de un programa innato, mientras que el de los humanos es resultado exclusivo de la experiencia; o también creer que los aspectos genéticos influyen antes del nacimiento y los ambientales sólo a partir del nacimiento; otra idea equivocada consiste en pensar que hay aspectos de la conducta humana que están genéticamente determinadas, y otras, sólo influidas por el entorno ambiental. La realidad es que todos los aspectos de la conducta humana son el resultado de la interacción entre genes y ambiente. Pero no es posible determinar qué parte o porcentaje corresponde a lo genético y qué parte a lo aprendido.

Las investigaciones actuales se orientan en la línea de estudiar casos de hermanos gemelos que se han criado por separado, para ver en qué medida han desarrollado conductas similares o diferentes ${ }^{51}$. Pero, a parte de la precariedad científica de estas investigaciones, en todas ellas se advierte que la conducta humana no está determinada ni por los genes ni por el ambiente, sino que es fruto de ambos componentes y de la libertad de cada individuo.

En la actualidad, otro modo de acercarse al estudio científico de la conducta humana es la denominada Psicología evolucionista, que persigue "afrontar el reto de analizar la conducta humana asumiendo, con todas sus consecuencias, el origen evolutivo de nuestra especie $\mathrm{e}^{\prime 52}$. Los pioneros de esta disciplina han sido J. H. Barkow, L. Cosmides y J. Tooby, con su libro fundamental The Adapted Mind: Evolutionary Psychology and the Generation of Culture ${ }^{53}$. Un autor importante $y$ muy conocido de esta disciplina es S. Pinker, discípulo de Chomsky y uno de los teóricos más interesantes acerca del origen del lenguaje humano ${ }^{54}$. Conscientes de que la conducta humana es una síntesis de mecanismos genéticos e influencias del entorno, los psicólogos evolucionistas intentan descubrir los mecanismos psicológicos que se han ido conformando en nuestra especie como resultado de su historia evolutiva, desde el momento en que apareció la especie hace más de dos millones de años. Esos 
mecanismos psicológicos serían los responsables de los principales rasgos de la conducta humana, como la capacidad intelectual, la agresividad, los comportamientos sexuales, la cooperación en sus diferentes niveles, la diversidad cultural y otros más. Se trataría, por tanto, de encontrar ese conjunto de rasgos psicológicos comunes que conformarían la naturaleza humana, conformada fuertemente por ingredientes genéticos. De todos modos, aunque Pinker se desmarca claramente del determinismo genético de la sociobiología, considera que muchos de sus planteamientos son correctos, y se muestra, de modo significativo, más duro con los críticos de la sociobiología, el grupo denominado Science for the People ${ }^{55}$, que las tesis deterministas de los sociobiólogos. Eso muestra que en la articulación de lo innato y lo aprendido, Pinker tiende a acentuar en gran medida el primer componente en detrimento del segundo, sin ser suficientemente consciente de que resulta difícil, por no decir imposible, distinguir la aportación de cada uno de esos dos componentes en aspectos como, por ejemplo, la medición de la inteligencia y en otros ámbitos del comportamiento de los individuos ${ }^{56}$.

\subsubsection{La singular estructura com- portamental de los seres humanos}

En definitiva, tras todas estas precisiones, parece que podemos concluir que la estructura compor- tamental del ser humano y la del resto de los animales es cualitativamente diferente.

Es cierto, como hemos indicado, que no es correcto generalizar acerca de los animales, defendiendo que su conducta se encierra dentro de un esquema innato EstímuloRespuesta (E-R). Los animales, sobre todo los superiores, además de sus capacidades innatas aprenden del entorno y les influye el ambiente. Pero sus capacidades cognitivas no pasan de un cierto nivel ni son capaces de una conciencia de segundo nivel como los seres humanos, ni son capaces de romper los constreñimientos biológicos como para poder elegir libremente entre diversas posibilidades de acción.

Si hacemos referencia a las investigaciones con las diferentes especies de grandes simios (chimpancés, bonobos, gorilas y orangutanes), hemos de reconocer que tienen grandes capacidades cognitivas que con anterioridad se minimizaban ${ }^{57}$. Y, aunque las primeras investigaciones estaban impregnadas de errores metodológicos que hacían pensar más en respuestas de amaestramiento que en respuestas con contenido cognitivo autónomo, investigaciones posteriores parecen avalar una riqueza interior que nos deslumbra y rompe muchos de nuestros esquemas anteriores. Todas las especies animales parecen tener su propio sistema de comunicación interna, pero eso no significa que 
tengan lo que se denomina teoría de la mente ${ }^{58}$, es decir, la capacidad de ponerse en el lugar de otro congénere. Pero es cierto que determinados animales superiores utilizan un modo de comunicación a través de gestos y de gruñidos que parece implicar un cierto contenido semántico. Incluso hay chimpancés que pueden llegar a utilizar el lenguaje de los sordomudos, o un lenguaje en que se utilizan fichas y teclado de ordenador. Hasta poseen un incipiente grado de autoconciencia, pues parecen reconocerse ante el espejo. $\mathrm{Y}$ hasta parecen capaces de emplear lo que se ha venido a llamar conductas maquiavélicas, puesto que tratan de engañar a otros semejantes, percibiéndose en esas conductas un alto grado de capacidad de ponerse en el lugar del otro.

¿Significa esto que podemos deducir que la diferencia entre la capacidad cognitiva y la estructura comportamental entre los hombre y los animales superiores, los grandes simios, es sólo cuantitativa, pero de ningún modo cualitativa? Pensamos que no. En este punto, como en los anteriores aspectos de que hemos hablado, se da una continuidad junto con una clara ruptura cualitativa. Es evidente que se da una continuidad: los seres humanos no innovan nada, hemos indicado ya con palabras de J. Ruffié, sino que lleva hasta un nivel de perfección extraordinario un conjunto de tendencias y cualidades que aparecen ya en diversas especies animales anteriores. Pero también se da un salto cualtitativo importante. Lo que nos diferencia respecto a las especies anteriores, incluso las más cercanas y mejor dotadas, es muy significativo.

a) Una mayor capacidad cognitiva, debida a nuestro extraordinario desarrollo cerebral, que nos ha permitido llegar a poseer pensamiento simbólico, recordar el pasado, anticipar el futuro, crear símbolos arbitrarios, etc.

b) La capacidad lingüística, que nos dota en este punto de una clara diferencia cualitativa no sólo en lo fonético, sino en lo semántico, sintáctico y pragmático ${ }^{59}$. La diferencia entre el supuesto lenguaje animal y el humano no es gradual, sino cualitativo (Bickerton y sus teorías sobre los lenguajes criollos o pidgin ${ }^{60}$ )

c) La autoconciencia, que no es un simple aumento de la autopercepción animal, sino un segundo nivel de conciencia.

d) La libertad y la capacidad moral, por lo que podemos afirmar que sólo los humanos somos animales éticos.

e) La complejidad social: nacemos dotados de la capacidad de ponernos en el lugar del otro ( $p s^{-}-$ cólogos innatos, Humphrey $\left.{ }^{61}\right)$, 
de modo que nuestro entorno ecológico más cercano y específico son los otros (entorno social), no tanto la naturaleza.

f) La apertura a la pregunta por el sentido (filosofía), la inevitabilidad de la muerte, la pregunta por el fundamento y el absoluto (religión), etc.

Todos estos ingredientes son suficientemente significativos como para que podamos afirmar que la diferencia entre los hombres y demás animales no es sólo cuantitativa sino cualitativa. Por tanto, estamos de acuerdo con Chomsky cuando considera que, a la vista de estas diferencias, no es correcto hablar con idénticas palabras para las acciones animales y las humanas, por ejemplo inteligencia o lenguaje, puesto que la diferencia es abismal y cualitativa. Es como decir que los seres humanos vuelan, porque son capaces de dar grandes saltos y permanecer en el aire durante un breve tiempo. Como tampoco vale creer que los simios podrán con el tiempo, y con el adiestramiento adecuado, llegar a dominar y entender el lenguaje humano y comunicarse adecuadamente con nosotros. Los que así piensan, dice también Chomsky, parecen imaginar que es razonable esperar que haya alguna isla desierta y desconocida en donde habitan aves con capacidad para volar pero que no vuelan, pero están esperando a que los hu- manos descubramos esa isla y les enseñemos a volar. Si la selección natural ha dotado a tales aves de la capacidad de volar, lo habrá hecho porque esa cualidad es valiosa para su supervivencia, y resulta absurdo que estén esperando a utilizarla hasta que algún ser humano les enseñe a utilizarla. Algo así parecen creer algunos sobre la supuesta capacidad intelectual y de lenguaje en los chimpancés y demás simios.

El ser humano, como consecuencia del proceso evolutivo, ha sido configurado de un modo tal que posee cualidades y un modo de comportamiento radicalmente nuevo y cualitativamente diferente al del resto de los animales. Lo esencial está en que nuestro comportamiento no está limitado por un programa genético y biológico, sino que se ha producido una ruptura, de modo que no tenemos estructuras comportamentales cerradas sino abiertas. Así, entre los estímulos que percibimos y las respuestas que tenemos que realizar, se da un hiato o vacío que tenemos que llenar de modo reflexivo. Es decir, tenemos que pensar y elegir entre diversas formas de responder. $Y$ esa es la condición de posibilidad biológica de nuestra libertad y de nuestra capacidad ética. Es la expresión de nuestra condición inmadura, como vimos, de nacer antes de tiempo, y de haber roto la lógica del desarrollo embrionario que siguen las demás especies. 
Así que los seres humanos no es que seamos más inteligentes o más complejos o capaces de interactuar con el entorno, sino que lo hacemos de otra manera, siguiendo una lógica o una estructura comportamental radicalmente diferente. $\mathrm{Zu}$ biri lo expresa acertadamente diciendo que al animal se le da la realidad bajo la formalidad de estimulidad, mientras que al ser humano, bajo la formalidad de reidad o de realidad. El ser humano está vertido a la realidad, y no a la mera estimulidad. No percibimos meros estímulos sino realidades, cosas reales. Y nuestra habitud, o modo de habérnoslas con la realidad es radicalmente diferente. El animal siente, mientras que el ser humano, consecuente con su estructura psicosomática, intelige sentientemente. Siente pero de modo inteligente. E intelige, pero de modo sentiente. Así, sus actos son complejos pero unitarios. Eso significa que el ser humano ha sido elevado a una nueva estructuración esencial, en la medida en que su animalidad ha sido elevada o configurada por una estructura nueva dotada de intelección. $\mathrm{Y}$ todos sus actos son al mismo tiempo sensibles e intelectivos, dándose en unos dominancia de lo sensitivo (digerir, respirar), y en otros, dominancia de lo intelectivo (pensar, decidir) ${ }^{62}$.

\section{4. ¿Ampliación de la" humani- dad" a los grandes simios?}

Si en los apartados anteriores nos hemos referido a quienes defienden un igualamiento entre la especie humana y los demás animales, merece hacer referencia a quienes en la actualidad también pretenden diluir la diferencia hombre-animales pero no tanto por un proceso de abajamiento del ser humano, sino por una elevación de determinadas especies animales, las de los denominados grandes simios, al nivel de lo humano. Este movimiento, liderado entre otros por P. Singer y T. Reagan, pretende la liberación animal y la defensa de los derechos de los animales, argumentando que la distinción que tradicionalmente se hace entre la especie humana y las de estos grandes simios basada en la racionalidad y la autonomía no es pertinente, sino que debe hacerse desde la capacidad para sufrir y gozar.

A partir de la época moderna, la ética se ha fundamentado y justificado desde la autonomía de la razón y del individuo. Kant nos enseñó que la persona humana, debido a su autonomía y racionalidad, es digna de respeto y sujeto de derechos, en la medida en que es un fin en sí misma y posee valor y no precio; esto es, no puede ser usada como medio para ningún otro fin o valor. Pero esta fundamentación racional fue puesta en cuestión posteriormente por el emotivismo y el utilitarismo. El emotivismo sostiene que la fuente de la moral son los sentimientos, puesto que el ser humano actúa moralmente llevado por los sentimientos y emociones, impulsado sobre todo 
por la compasión. Además, el utilitarismo, de la mano de J. Bentham y de J. Stuart Mill, sostiene que la bondad y maldad de los actos no se advierten en sí mismos sino por sus consecuencias.

Por tanto, nos encontramos con dos modelos de ética muy diferentes, apoyados cada uno en un modelo distinto de persona. Mientras la propuesta ética kantiana es una propuesta formal y procedimental (no podemos llegar a una ética material universal, sino a una forma o procedimiento universalizable: el imperativo categórico) y deontológico (una ética basada en principios, obtenidos a través del imperativo categórico, de obligado cumplimiento para todos), el utilitarismo emotivista defiende una ética basada en sentimientos y consecuencialista (los principios no valen en sí, sino por sus consecuencias positivas). Igualmente, sus modelos antropológicos son diferentes. Mientras el modelo kantiano se basa en un humanismo antropocéntrico, basado en la autonomía y en la razón (es la razón y no los sentimientos lo que distingue y caracteriza a las personas), el emotivismo utilitarista se apoya en una idea de persona basada en la capacidad de sufrir y de gozar. Todo ser capaz de sufrir y de gozar tendrá derecho a que se respeten sus sentimientos y sus intereses, con lo que en la actualidad hay teóricos que pretenden introducir en la clase o grupo de personas a determinados animales dotados de una especial sensibilidad para el goce y el sufrimiento.

De todos modos, los planteamientos de los dos teóricos más influyentes en la defensa de los supuestos derechos de los animales, $P$. Singer y T. Reagan, son un tanto diferentes.. P. Singer, apoyado en la tradición emotivista y utilitarista, considera que el mal es un mal que debe ser evitado en la medida de lo posible ${ }^{63}$. En realidad, estos derechos no los extiende a todos los animales, sino a los grandes simios ${ }^{64}$, por lo que su postura es considerada por los más radicales como reformista. Tacha a las diversas posturas humanistas, sean religiosas o laicas, de especieísmo, puesto que defienden un etnocentrismo humano según él ilegítimo, en la medida en que la diferencia entre los humanos y los animales superiores (los grandes simios) no sería esencial, sino gradual, y estaría basada en la común capacidad de sufrir y de gozar. Ahora bien, $P$. Singer es consciente de que en caso de conflicto entre determinados derechos de los humanos y de los simios, los derechos de los humanos pasarían por delante, pero eso no supondría tener que afirmar que es preferible cualquier sufrimiento animal respecto al sufrimiento humano, ni que se pueda legitimar cualquier sufrimiento animal para satisfacer cualquier deseo o capricho humano.

T. Reagan, en cambio, defiende los derechos de los animales apoyándose en tesis principialistas y 
deontológicas, en la medida en que defiende los derechos de los animales en función de su valía intrínseca ${ }^{65}$. Por tanto, no se trata, como en el caso de P. Singer, de defender los derechos de los animales porque también ellos sufren y gozan, sino porque los animales en general, y más aún los superiores, como los mamíferos, poseen una vida interior muy compleja y evolucionada, que les capacita para ser sujetosde-una-vida y les dota de un valor inherente. Esta supuesta inherencia ontológica y ética es la que le empuja a Regan a pedir que se respete la dignidad de los animales y a que no se les haga sufrir. Esta petición no tiene recortes ni paliativos, puesto que Reagan aplica un valor inherente a todos los animales, y en general a todos los seres vivos, $y$ por ello todos, hombres y animales, tenemos los mismos derechos morales básicos.

Estaríamos, pues, ante propuestas que defienden, aunque con razones diferentes, una ampliación de la idea de persona, que no abarcaría tan sólo a la especie humana sino que también acogería algunas especies superiores, según la línea de Singer, o la de todos los animales, como propone T. Reagan, e incluso, según los ecologistas más radicales, a todos lo seres vivos. Muchos de estos teóricos se apoyan en la propuesta de D. Dennett de entender que el concepto de persona es un concepto borroso y se puede aplicar a determinados animales ${ }^{66}$. Las condiciones que, según Dennett, debiera tener quien aspire a ser considerado una persona serían: ser racionales, poseer adscripciones intencionales, ser sujeto de consideraciones morales, capacidad para adoptar una actitud recíproca de respeto, usar lenguaje, y disponer de autoconciencia. Estas cualidades, que cualquier humanista aceptaría en principio, por parecer que son suficientemente significativas como para mantener la distancia cualitativa respecto al resto de los animales, en el contexto de Dennett sirven para defender una idea borrosa de persona, en la medida en que esas seis condiciones las cumplirían también los animales superiores.

Detenerse a desmontar todos estos presupuestos nos llevaría demasiado tiempo. Estos planteamientos de Dennett y sus seguidores caen en el mismo error que hemos visto en el apartado anterior referido a la diferencia entre hombres y animales en relación a su estructura comportamental: insisten en los parecidos y en la incipiente continuidad entre esas características humanas, que en los animales sólo se haIlan apuntadas y en embrión. Sólo para quien parta de una concepción filosófica reduccionista y naturalista podrá resultar convincente la visión de una mera diferencia cuantitativa entre hombres y animales, como les parecerá también una mera diferencia cuantitativa la existente entre el salto de una persona y el vuelo de 
un pájaro, según en señalado símil de N. Chomski.

En los animales se hallan presentes, como en embrión, casi todas las cualidades que en los seres humanos llegan a su madurez y concreción, desde la conciencia y la comunicación, hasta la capacidad técnica de construir herramientas. Pero de ninguna manera se pueden ignorar las características específicas del ser humano, como son la libertad y la capacidad ética, el lenguaje articulado y la apertura a la cuestión del sentido, entre otras. Si no queremos introducir confusiones inaceptables, hemos de reconocer que sólo los individuos que poseen estas características pueden ser considerados como personas.

Eso no quita que no debamos crecer en aprecio y respeto por los animales y la naturaleza en general, y proponer normas de respeto y de protección de biosfera y de las diferentes especies animales, aceptando incluso que denominemos a eso derechos de los animales ${ }^{67}$. Pero otra cosa es que diluyamos el concepto de persona, atribuyendo características exclusivas de los humanos a determinados animales. De ahí que pensemos que es totalmente legítimo seguir defendiendo un humanismo antropocéntrico, complementado con la defensa de una normativa que defienda un trato respetuoso con las diferentes especies animales. Igualmente, nos parece también adecuado completar la idea tradicional de persona, no basándola exclusivamente en su racionalidad sino también en su sensibilidad, en la medida en que el ser humano es una unidad biocultural, o lo que es lo mismo, una unidad psico-orgánica, en la que no sólo cuenta lo psíquico y racional sino también la sensibilidad y los sentimientos. Se trata, por tanto, de acogernos a un nuevo paradigma en la comprensión de lo humano, complementario con un nuevo talante en la relación con los animales, que recoja lo más valioso de los dos paradigmas anteriores, el racional y el emotivo ${ }^{68}$. Este nuevo paradigma nos permite conjugar el humanismo antropocéntrico con una nueva praxis en relación con los animales, basada en el respeto.

\section{La específica y singular estructura esencial de la especie humana}

Como resultado de todo el recorrido que hemos hecho, se desprende de una forma bastante plausible, que el ser humano, a pesar de los parecidos inevitables con el resto de los animales, en especial con los que se hallan más cercanos en el proceso evolutivo, representa una especie totalmente singular, con una diferencia no meramente cuantitativa sino cualitativa. Lo hemos ido viendo en cada uno de los 
diferentes apartados de la comparación que hemos ido analizando.

a) En la comparación desde el punto de vista genético, veíamos que los datos de que disponemos parecían favorecer a la postura reduccionista, si nos limitamos a una mirada meramente naturalista. Las diferencias entre hombres y chimpancés son pocas, sólo un $1 \%$ de su genoma. Pero ya veíamos que teníamos que hacer sobre ello varias precisiones: en primer lugar, las investigaciones sobre el genoma nos indican que estamos todavía lejos de haber desentrañado todos los secretos de su estructura y del modo como parecen funcionar los códigos genéticos para expresarse en el ámbito fenotípico, en la medida en que se halla en cuestión la idea de gen, y se advierte que una gran parte del genoma no se sabe si tiene alguna función y cuál es en concreto; en segundo lugar, cada vez está más clara la insuficiencia del código genético para explicar la realidad de un ser vivo, cobrando progresiva importancia el trayecto epigenético que une ambos extremos (genotipo y fenotipo), como nos indican la biología molecular y del desarrollo; además, en tercer lugar, en el ejercicio comparativo de genomas, más significativo que la mera comparación cuantitativa entre genes es la importancia de las consecuencias fenotípicas que producen el correspondiente porcentaje diferenciador; en concreto, está claro que ese $1 \%$ de singularidad humana es el responsable de las diferencias morfológicas, del especial desarrollo embrionario, y, sobre todo, de la específica estructura comportamental del ser humano, y este aspecto es el realmente importante. En definitiva, lo significativo no es el porcentaje de parecidos y diferencias, sino las consecuencias tan especiales que esas pequeñas diferencias generan en el fenotipo morfológico, y más aún en el conductual, en la especie humana.

b) Si hacemos referencia al aspecto anatómico-morfológico, volvemos también a encontrarnos con la dialéctica continuidad-ruptura: los parecidos anatómico-morfológicos son muy amplios, quedando claro que la especie humana está entroncada evolutivamente a la familia de los hominoideos; pero las diferencias son también muy significativas, desde la postura erguida permanente, la utilización inteligente de la mano, y sobre todo la posesión de un cerebro extraordinariamente grande y específicamente estructurado que nos dota de especiales capacidades cognitivas y de la posibilidad de 
utilizar un lenguaje articulado, complementado con la posesión de una laringe adaptada como aparato fonador.

c) En relación al especial modo de desarrollo ontogenético que poseemos como especie, se advierte que aquí se halla la base de nuestra especial estructura comportamental, en la medida en que nacemos antes de tiempo, como animales prematuros, con el aspecto del feto de un mono (neotenia) y necesitados de una más prolongada infancia y proceso de aprendizaje, representando esta prematuridad la base biológica de nuestra libertad y la necesidad de poner en marcha nuestras más complejas capacidades cognitivas para dotarnos de cultura y construir un mundo a nuestra medida. Los defensores de acortar distancias entre hombre y animales siguen aportando supuestas evidencias sobre la existencia de culturas animales. Pero volvemos a repetir que tales atisbos de parecido con lo humano es un aspecto más de la tendencia en las especies animales anteriores de poseer aspectos o tendencias embrionarias de lo que después, en la especie humana, serán características más maduras y complejss, de naturaleza cualitativamente diferente.

d) Donde la diferencia es más amplia, explícita e incontestable es en el ámbito de la conducta, de la estructura comportamental. Hemos indicado que la conducta, tanto en el ser humano, y también en la mayoría de los animales superiores, es una síntesis de genética y aprendizaje. Pero la diferencia entre la estructura comportamental humana y animal es abismal: los animales, incluso los más inteligentes como los chimpancés y los bonobos, están más sometidos a su herencia genética, y el componente de aprendizaje y de creatividad es mucho menor, no advirtiéndose en ellos ningún atisbo de libertad; en cambio, en la especie humana, la herencia genética es más abierta, no está constituida por unas pautas de comportamiento cerradas, sino que queda en manos de la propia decisión del individuo. De ahí que, como indicaba Gehlen ${ }^{69}$, entre el estímulo y la respuesta el ser humano tiene que poner, por necesidad, un hiato, un paréntesis de decisión y de libertad, característica exclusiva de la especie humana.

En definitiva, en el ser humano se da, como ya lo hemos dicho, una síntesis de continuidad y de ruptura evolutiva en relación con el resto de los animales. $Y$ en lo que tiene de ruptura, puede verse el aspecto negativo, su deficiencia biológica, pero también el positivo: su extraordinaria capacidad cognitiva y 
su libertad, que le obligan a decidir en cada momento entre diversas posibilidades de actuación.

El ser humano es, pues, la única especie cuya estructura esencial es una síntesis de biología y cultura. La biología es la condición de posibilidad de la cultura, pero no agota ni determina su lógica o racionalidad interna. En el ser humano, la biología se ha abierto y ha sido subsumida por un nivel de realidad nuevo: lo psíquico o espiritual. De tal forma que sin dejar de ser un animal, el ser humano es una estructura esencial nueva: unidad psico-orgánica.

Considero que los planteamientos metafísicos y antropológicos de Xavier Zubiri siguen siendo uno de los más adecuados para definir la especificidad de lo humano, entendiéndolo como una realidad entroncada y situada dentro del dinamismo total de la realidad ${ }^{70}$. La realidad es esencialmente dinámica, está constitutivamente dando de sí ${ }^{71}$, configurándose diferentes modos o niveles de dinamismos, desde el dinamismo de la variación hasta el de la suidad, con sus tres dimensiones: personal, social e histórica. Todo surge desde la materia, complejificándose sistémicamente hasta dar de sí la realidad viva, y posteriormente el psiquismo humano. La realidad humana es una conjunto sustantivo de notas, que forma una estructura psico-orgánica única, conformada a su vez por dos subestructuras: la psíquica y la orgánica. La subestructura psíquica le hace ser inteligente, esto es, su habitud o el modo de habérselas con la realidad consiste en estar abierto a la realidad en cuanto tal. En cuanto realidad psico-orgánica, sus actos son de naturaleza sensible e inteligente al mismo tiempo (intelección sentiente).

Así, el ser humano siente, como el resto de los demás animales, de tal modo que la realidad se le da en impresión. Pero es un sentir inteligente, en la medida en que su animalidad ha sido elevada a una estructura nueva: la psíquica, consecuencia de las mutaciones genéticas y la cerebralización. De ahí que el ser humano es el resultado de la emergencia de una nueva estructuración cerebral, que le ha dotado de una mente capaz de escapar del constreñimiento biológico y genético, para abrirse al nivel de la suidad: la realidad humana es una naturaleza abierta, de una complejidad tal que tiene que hacerse cargo de sí misma, de su propia realidad y cargar libre y responsablemente de ella misma, en diálogo comunitario con las demás realidad humanas.

En definitiva, en función de la específica estructura sustantiva de la realidad humana, posee muchos elementos comunes con los demás animales, y advertimos en ellos apuntados y en embrión muchas de las características que en el ser humano han llegado a su pleno 
cumplimiento y realización. Por eso que no nos extraña ver en los chimpancés y demás especies de simios, tantas similitudes genéticas, morfológicas e incluso conductuales. Pero tampoco nos debería extrañar que sigamos afirmando al mismo tiempo la distancia cualitativa propia de la condición humana: autoconciencia, libertad y responsabilidad, lenguaje articulado, capacidad de construcción de complejas herramientas, complejo entramado social, capacidad de goce estético, apertura a la pregunta por el fundamento y a la búsqueda del absoluto, etc.

La unidad biocultural del ser humano es una expresión de su unidad psico-orgánica, tal y como la defienden los emergentismos sistémicos, entre cuyos defensores se sitúan M. Bunge, K. Popper, J. Searle, o J. Monserrat ${ }^{72}$, o también el estructurismo dinámico de X. Zubiri y P. Laín Entralgo ${ }^{73}$. Este modo de entender las relaciones entre la mente y el cuerpo permite superar tanto los materialismo o monismos fisicalistas y los dualismos, para entender, por el contrario, la realidad humana como una estructura o sistema único, resultado de un proceso evolutivo que ha experimentado sucesivas complejificaciones, de modo que la mente viene a ser un modo nuevo y específico de estructuracion y sistematización del cerebro y del conjunto del cuerpo humano.

Esta visión dinámica y saltacionista de la realidad está confirmada en todos los niveles de la realidad de nuestro mundo. Pequeños cambios acumulados Ilegan a desencadenar un salto cualitativo, que exige un nuevo nivel de realidad, organizado con una nueva estructuración. En estos saltos cualitativos, el nivel inferior es condición de posibilidad del superior, al que subtiende dinámicamente (Zubiri). Pero el nivel superior no se reduce al inferior, aunque se apoye en él. De tal forma que la novedad que supone la emergencia del nuevo nivel, es una novedad imprevisible e irreductible. Imprevisible, porque no puede ser prevista desde el nivel inferior, e irreductible, porque las leyes y la lógica con la que está configurado y constituido el nivel emergente no puede ser reducido a las leyes del nivel inferior. Así, la psicología no puede reducirse a la biología, ni ésta a la física.

En consecuencia, esta singularidad y especial densidad ontológica de la realidad humana hace que pueda ser defendido un teoría humanista y antropocéntrica de la realidad humana, que nos permite defender también la centralidad ética del ser humano frente a las teorías que pretenden diluir la línea divisoria de la humanidad y de la personalidad que separa a hombres y al resto de los animales. Sólo la especie humana está vertida a la moralidad, porque sólo ella tiene capacidad ética y capacidad de apropiarse de posibilidades para hacerse y realizarse. Eso no quita 
que las demás realidades, animales, plantas y el resto de la materia, posean su propia densidad ontológica, $y$, en consecuencia, el ser humano deba comportarse frente a ellos no como un déspota sino como un cuidador y administrador inteligente y responsable. Y bajo este prisma es como tiene sentido la sensibilidad ecológica y proyectos como el Gran Simio y otros semejantes.

En consecuencia, el ser humano puede seguir siendo considerado el centro de la creación, y el único al que se le pueden pedir responsabilidades, tanto en relación a sí mismo, como también en relación a sus semejantes y al resto de la creación. Y es a través de la puesta en marcha de su capacidad de razonar y de llegar a consensos racionales como se podrá establecer cuáles son las obligaciones que nos corresponden en relación al ecosis-

Notas

1 Cfr. LANDMANN, M., Antropología filosófica. Autointerpretación del hombre en la historia y en el presente, México, UTEHA, 1961.

2 Cfr. BEORLEGUI, C., Antropología filosófica. Nosotros: urdimbre solidaria y responsable, Bilbao, Universidad de Deusto, 1999, 2004 (2 ${ }^{\mathrm{a}}$ ed.), 35-37.

3 Cfr. BUBER, M., ¿QQué es el hombre?, México, FCE, 1976 (9ª ed.). tema y a sus diferentes realidades integrantes, tanto seres vivos como no vivos.

Pensamos, pues, que si los múltiples y complejos avances de las diferentes ciencias van representando retos importantes para la comprensión de nuestro ser como humanos, estos mismos saberes científicos nos aportan suficientes apoyaturas como para seguir defendiendo una visión humanista, y también cristiana, del ser humano. Somos, está claro, una especie más en el conjunto de la biosfera, pero dotada de una singular naturaleza, que nos ha dotado de especial inteligencia, libertad, responsabilidad, lenguaje, socialidad, y demás cualidades específicas, con ayuda de las cuales podemos ser conscientes de la acción de Dios que nos ha llamado a la existencia y nos ofrece gratuitamente su salvación.

4 Cfr. GARCÍA BACCA, J. D., Antropología filosófica contemporánea, Caracas, UCV, 1947, cap. 2, "El hombre como tema y como problema" (nueva edición: Barcelona, Anthropos, 1982.

5 C fr. DOBZHANSKKY, Th.,Genetics and the Origin of Species, Columbia University Press, 1937; E. Mayr y W. Provine, The Evolutionary Synthesis, Harvard University Press, 1980; G. Simpson, The major features of evolution, Columbia University Press, 1953. 
6 Cfr. MONOD, J., El azar y la necesidad, Barcelona, Barral, 1977.

7 Cfr. SINGER, P., Liberación animal, Madrid, Trotta, 1999; Id., Una izquierda darwiniana. Política, evolución y cooperación, Barcelona, Crítica, 2000; CAVALIERI, P./ SINGER, P. (eds.), El proyecto "Gran Simio". La igualdad más allá de la humanidad, Madrid, Trotta, 1998; BEORLEGUI, C., “¿Hacia un humanismo trans-antropocéntrico? Peter Singer y los derechos de los animales”, Realidad, 2001, $\mathrm{n}^{\circ} 80$, 199-236; Id., "Ética animal e idea de persona”, en GUIBERT UNCÍN, J.M./ORELLA UNZUÉ, J. L. (eds.), Preguntas éticas en cuestiones disputadas hoy, San Sebastián, Universidad de Deusto, 2005, 317-335. .

8 Cfr. BEORLEGUI, C., "Filosofía de la mente: visión panorámica y situación actual", Realidad, 2007, n ${ }^{\circ} 111$, 121-160; Id., "Los emergentismos sitémicos: Un modelo fructífero para el problema mente-cuerpo", Pensamiento, 62 (2006), 391-439.

9 Cfr. MOREY, M., El hombre como argumento, Barcelona, Anthropos, 1987; LORITE MENA, J., La filosofía del hombre, o el ser inacabado, Estella, Verbo Divino, 1992; BEORLEGUI, C., Antropología filosófica. Nosotros: urdimbre solidaria y responsable, o.c., caps. $2^{\circ}$ y $4^{\circ}$.

10 Barcelona, Tusquets, 2006.

11 Cfr. ZUBIRI, X., Inteligencia y Ra- zón, Madrid, Alianza/Sociedad de Estudios y Publicaciones, 1983.

12 Cfr. HAEFFNER, G., Antropología filosófica, Barcelona, Herder, 1986, 20-26.

13 Cfr. RIEDLEY, Matt, Genoma. Autobiografía de una especie en 23 capitulos, Madrid, Taurus, 2000; DULBECCO, R., Los genes y nuestro futuro, Madrid, Alianza, 1999; SULSTON, J. y FERRY, G., El bilo común de la bumanidad. Una historia sobre la ciencia, la politica, la ética y el genoma humano, Madrid, Siglo XXI, 2003; NÚÑEZ DE CASTRO, I., “Análisis antropológico del Proyecto Genoma Humano" (manuscrito sin publicar).

14 Cfr. WATSON, J. D., The double belix (La dobre hélice); Id., Genes, chicas y laboratorios, Barcelona, Tusquets, 2006.

15 Cfr. bibliografía: AYALA, F. J., Origen y evolución del hombre, Madrid, Alianza, 1980, cap. VI; RUSE, M., Filosofía de la biología, Alianza, 237 y ss.; BERTRANPETIR, J,/ JUNYENT, C., Viaje a nuestros origenes. Una historia biológica de la especie humana, Barcelona, Península, 2000; JORDAN, B., Los impostores de la genética, Barcelona, Península, 2000; FOX KÉLLER, E., El siglo del gen. Cien años de pensamiento genético, Barcelona, Península, 2002.

16 Cfr. AYALA, F. J., o. c., pp. 158161. 
17 AYALA, F. J., o.c., 160-161. Cfr. RUFFIÉ, J., De la Biologie á la Culture, Paris, Flammarion, 1976 (De la biología a la cultura, Barcelona, Muchnik Editores, 1982, 278 y ss.).

18 Cfr. NÚÑEZ DE CASTRO, I., o.c., p. 3.

19 Estas letras significan: $\mathrm{pb}=$ pares de bases, refiriéndose a los emparejamientos de las cuatro bases nitrogenadas ya sabidas, mientras que $\mathrm{k}$ equivale a la cantidad de pares de bases existentes en el conjunto del genoma, cantidad similar a 10 al cubo. Cuando las cantidades son mayores, se utiliza, en vez de $\mathrm{k}$, el símbolo $\mathrm{M}$, equivalente a 10 a la sexta. Cfr. I. Núñez de Castro, o.c., p. 3.

20 Sobre los datos comparativos entre el hombre y el chimpancé, cfr. The chimpanzee sequencing and análisis Consortium, "Initial séquense of the chimpanzee genome and comparison with the human genome", Nature 437, 2005, pp. 69-87.

21 Cfr. WATSON, James D., "The Human Genome Project: past, present and future", Science, 248. 1990, 44-48; NÚÑEZ DE CASTRO, I., o.c., pp. 1-12.

22 Cfr. Ibídem, o.c., p. 5.

23 NÚÑEZ DE CASTRO, I., o.c., p. 6. Cfr. Id., "La indefinición fundamental de las ciencias biológicas", en DOU, A. (ed.), Fragmentariedad de las ciencias, Bilbao, Mensajero/ Biblioteca Fomento Social, 1985, 143-147; FONTANILLE, J., "Dieciocho definiciones sobre el gen", $\mathrm{La}$ Recherche (Elementos?), 2003, vol. $10, n^{\circ} 50$, p. $17 .$.

24 NÚÑEZ DE CASTRO, I., o.c., pp. 6-7.

25 Cfr. MEIER, R., Comportamiento animal. Un enfoque evolutivo $y$ ecológico, Madrid, McGrawHill, 2001. p. 35; NÚÑEZ DE CASTRO, I.,o.c., p. 9.

26 NÚÑEZ DE CASTRO, I., o.c., p. 10.

27 Ibídem, p. 12.

28 Jared DIAMOND, en su libro The tirad chimpanzee: the evolution of the future of the human animal, N. York, Harper Perennial, 1993, propone que al ser humano habría que situarlo dentro de las otras dos especies de chimpancés, el chimpancé común (Pan trogrodytes) y el chimpancé enano, llamado también bonobo (Pan panicus), o bien, incluir a estas dos especies de chimpancés en el género homo, y denominar a los bonobos, Homo panicus, y al chimpancé común, Homo troglodytes. Cfr. J. DIAMOND, "El tercer chimpancé”, en P. CAVALIERI y P. SINGER, El proyecto "Gran simio". La igualdad más allá de la humanidad, Madrid, Trotta, 1998, 115-132. 
29 Cfr. RUFFIÉ, J., De la biología a la cultura, Barcelona, Muchnik Editores, 1982.

30 Cfr. AYALA, F. J., o.c., 153-158; LAÍN ENTRALGO, P., El cuerpo humano. Teoría actual, Madrid, Espasa-Calpe, 1989.

31 O.c., 154.

32 Cfr. Ibídem, p. 155.

33 Cfr. COPPENS, Y., La rodilla de Lucy. Los primeros pasos hacia la bumanidad, Barcelona, Tusquets, 2005.

34 Cfr. WILSON, F. R., La mano. De cómo su uso configura el cerebro, el lenguaje y la cultura, Barcelona, Tusquets, 2002.

Cfr. MORGAN LLAMAN, J., El cerebro en evolución, Barcelona, Ariel, 2003; Braillon, M. G., El sistema nervioso central, Madrid, Alambra, 1980; GOLDBERG, E., El cerebro ejecutivo, Barcelona, Crítica, 2002 .

36 Cfr. BERMÚDEZ DE CASTRO, J. $\mathrm{M}^{\mathrm{a}}$, El chico de la Gran Dolina. En los orígenes de lo humano, Barcelona, Crítica, 2002, cap. 7, "El reloj biológico de los dientes”, pp. 93-109.

37 Cfr. LIEBERMAN, Ph., "On the evolution of language: A unified view", Cognition, 1973, no 2 ("Un enfoque unitario de la evolución humana”, en V. SÁNCHEZ DE
ZABALA (ed.), Sobre el lenguaje de los antropoides, Madrid, Siglo XXI, 1986, 147-203); LAITMAN, J. T.,"El origen del lenguaje articulado", Mundo Científico, 1986, $\mathrm{n}^{\circ}$ 64, 1182-1191.

38 Cfr. LAÍN ENTRALGO, P., o.c., pp. 62-63; LACADENA, J. R., Genética y Bioética, Madrid/Bilbao, UPCO/Desclée de Brouwer, 2002, 15-71..

39 Cfr. CHRISTEN, Y., El hombre biocultural, Madrid, Cátedra, 1989, p. 57.

40 Cfr. CHRISTEN, Y., o.c., p. 58.

41 Cfr. Die Biologie und das neue Menschenbild, Berna, 1942.

42 Cfr. MAIER, R., Comportamiento animal. Un enfoque evolutivo y ecológico, o. c., 4-6.

43 Cfr. THORPE, W. H. , Breve historia de la etología, Madrid, Alianza, 1982; BEORLEGUI, C., "El reto de la biología a la antropología: De la etología a la sociobiología”, Letras de Deusto, 16 (1986), no 34, 37-69.

44 Cfr. WILSON, E. O., Sociobiología. La nueva sintesis, Barcelona, Omega, 1980; Id., Sobre la naturaleza bumana, México, FCE, 1980; RUSE, M. , Sociobiología, Madrid, Cátedra, 1983; DAWKINS, R. , El gen egoísta, Barcelona, Labor, 1979. 
45 Cfr. RUSE, M.,Sociobiología, o.c.

46 Cfr. WILSON, E. O. ,On Human Nature, Cambridge, Massachussets, 1978 (Sobre la naturaleza bumana, México, FCE, 1980).

47 WILSON, E. O., Sobre la naturaleza humana, p. 167.

48 Cfr. SOBER, E. y WILSON, D. S. , El comportamiento altruista. Evolución y psicología, Madrid, Siglo XXI, 2000.

49 Cfr. AYALA, F. J., Origen y evolución del hombre, Madrid, Alianza, 1980, cap. VII; BEORLEGUI, C. , "El reto de la biología a la antropología. De la etología a la sociobiología”, o.c.

50 Cfr. SAHLINS, M. , Uso y abuso de la biología, Madrid, Siglo XXI, 1982; R. LEWONTIN, S. ROSE y L. I. KAMIN, No está en los genes. Racismo, genética e ideología, Barcelona, Crítica, 1987.

51 Cfr. PLOMIN, R. , DE FRIES, J. C. , MECCLEAM, G. E.y MCGUFFIN, P. , Genética de la conducta, Barcelona, Airel, 2002; WRIGHT, W. , Asi nacemos. Genes, conducta, personalidad, Madrid, Taurus, 2000;RIDLEY, M. , Qué nos hace humanos, Madrid, Taurus, 2004.

52 Cfr. CASTRO, L. , LÓPEZFANJUL, C. y TORO, M. A. , A la sombra de Darwin. Las aproximaciones evolucionistas al comportamiento bumano, Madrid, Siglo XXI, 2003, 130.

53 New York, Oxford University Press, 1992.

54 Cfr. PINKER, S., The Blank Slate, Nueva York, Penguin, 2002 (trad. cast., La tabla rasa. La negación moderna de la naturaleza humana, Madrid, Alianza, 2003); BEORLEGUI, C. , "A vueltas con la naturaleza humana”, ARREGUI, J. V. (ed.), Debate sobre las antropologías", Sevilla, Themata, 2005, $\mathrm{n}^{\circ} 35,139-150$.

55 Entre ellos se sitúan Lewontin, Kamin, Rose y S. J. Gould. Cfr. LEWONTIN/KAMIN/ROSE, No está en los genes, o.c.; LEWONTIN, R. C. , El futuro del genoma bumano y otras ilusiones, Barcelona, Paidós, 2001, cap. $1^{\circ}$; GOULD, S. J., La falsa medida del hombre, Barcelona, Antoni Bosch,, 1984.

56 Cfr. BEORLEGUI, C., "A vueltas con la naturaleza humana”, o.c., pp. Pp. 141 y ss.

57 Cfr. De WAAL, Frans, La politica de los chimpancés, Madrid, Alianza, 1993; Id., Bien natural. Los orígenes del bien $y$ del mal en los humanos y otros animales, Barcelona, Herder, 1997; Id., Primates y filósofos. La evolución de la moral del simio al hombre, Barcelona, Paidós, 2007.

58 Cfr. PREMACK, D.y WOODRUFF, G. , "Does the chimpanzee have a theory of mind?", Behavioral 
and Brain Sciences, 1978, $\mathrm{n}^{\circ}$ 1, 515526 (trad. cast.:" ‘Tiene el chimpancé una teoría de la mente?", en MARTÍ, E. , Construir una mente, Barcelona, Paidós, 1997, pp. 137 178); PREMACK, D. , "Does the chimpanzee have a theory of mind?", BYME, R, y WHITEN, A. (comps.), Machiavellian Intelligence, Oxford, Science Publication, 1988.

59 Cfr. LORENZO, G./LONGA, V. M., Homo loquens. Biología y evolución del lenguaje, Lugo, Tris Tram, 2003; BEORLEGUI, C., "La capacidad lingüística del ser humano: una diferencia cualitativa", Thémata. Revista de Filosofía, 2006, no 37, 139168.

Cfr. BICKERTON, D., Lenguaje y especie, Madrid, Alianza, 1994.

61 Cfr. HUMPHREY, N. L., La reconquista de la conciencia. Desarrollo de la mente humana, México, FCE, 1987; Id., La mirada interior, Madrid, Alianza, 1993; Id., Una historia de la mente. La evolución y el nacimiento de la conciencia, Barcelona, Gedisa, 1995.

62 Cfr. ZUBIRI, X., Sobre la esencia, Sociedad de Estudios y Publicaciones, Madrid, 1972; Id., Inteligencia sentiente, 3 vols., Madrid, Alianza/Sociedad de Estudios y Publicaciones, 1980-82; Id., Sobre el hombre, Madrid, Alianza/ Sociedad de Estudios y Publicaciones, 1986; Id., Estructura dinámica de la realidad, Madrid, Sociedad de Estudios y Publicaciones, 1989.
63 Cfr. SINGER, P., Liberación animal, Madrid, Trotta, 1999; Id., Desacralizar la vida humana. Ensayos sobre ética, Madrid, Cátedra, 2003; BEORLEGUI, C. , "¿Hacia un humanismo trans-antropocéntrico? Peter Singer y los "derechos" de los animales", Realidad (UCA, San Salvador), 2001, no 80, 199-236; Id., "Etia animal e idea de persona", en GUIBERT, J. M.y ORELLA, J. L. (eds.), Preguntas éticas en cuestiones disputadas boy. In memoriam de Juan Plazaola Artola, S. I., San Sebastián, Universidad de Deusto, 2005, 317-335;TORRALBA, F. , ¿Qué es la dignidad humana? Ensayo sobre Peter Singer, Hugo Tristram Engelhardt y John Harris, Barcelona, Herder/Instituto Borja de Bioética, 2005.

64 Cfr. CAVAliERI, P.y SINGER, P. (eds.), El proyecto “Gran Simio”. La igualdad más allá de la humanidad, Madrid, Trotta, 1998.

65 Cfr. REGAN, T. , Animal Rights, Berkeley, University of California Press, 1983; Id., "Poniendo a las personas en su sitio”, Teorema, XVIII/2 (1999), 17-37.

66 Cfr. DENETT, D. , "Conditions of Personhood", en Brainstorms. Philosophical Essays on Mind and Psychology, Montgomery, Bradford Books, 1976.

67 Así lo defiende un etólogo tan cercano a posturas antropomórficas en 
relación con los primates como Fras De Waal, en Primates y filósofos. La evolcuón de la moral del simio al hombre, Barcelona, 2007, pp. 105111.

68 Cfr. GRACIA. D. , "Los animales en la tradición occidental”, en LACADENA, J. R. (eds.), Los derechos delos animales, Madrid/Bilbao, UPCO/Desclée de Brouwer, 2002, 134-150.,

69 Cfr. GEHLEN, A. , El hombre, Salamanca, Sígueme, 1980; SEQUEIROS, L. , “Arnold Gehlen (1904-1976). La búsqueda de una fundamentación biológica para la antropología filosófica”, enALARCOS MARTÍNEZ, F. J.(ed.)., La moral cristiana como propuesta. Homenaje al profesor Eduardo López Azpitarte, Madrid, San Pablo, 2004, 683-700; Id., "Biología y conducta humana. Reflexiones desde la antropología filosófica de Arnold Gehlen (1904-
1976)", texto de discusión con este escrito; BEORLEGUI, C. , Antropología filosófica, o.c., 393-432.

70 Cfr. ZUBIRI, X., Sobre el hombre, Madrid, Alianza/Fundación Xavier Zubiri, 1986.

71 Cfr. ZUBIRI, X. , Estructura dinámica de la realidad, Madrid, Alianza/ Fundación Xavier Zubiri, 1989.

72 Cfr. BEORLEGUI, C. , "Los emergentismos sistémicos: un modelo fructífero para el problema mentecuerpo", Pensamiento (en vías de publicación).

73 Cfr. LAÍN ENTRAlgO, P. , Cuerpo y alma. Estructura dinámica del cuerpo humano, Madrid, EspasaCalpe, 1991; Id., "El problema almacuerpo en el pensamiento actual”, en MORA, F. (ed.), El problema cerebro-mente, Madrid, Alianza, 1995, 17-35. 